\title{
Simplified method for calculating SNCR system efficiency
}

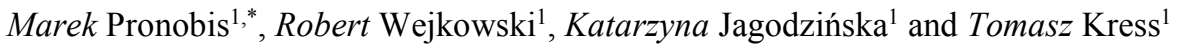 \\ ${ }^{1}$ Division of Boilers and Steam Generators, Institute of Power Engineering and Turbomachinery, \\ Silesian University of Technology, Konarskiego 20, 44-100 Gliwice, Poland
}

\begin{abstract}
SNCR (Selective Non-Catalytic Reduction) technology is aimed at reducing $\mathrm{NO}_{\mathrm{x}}$ emissions. SNCR efficiency is appropriately high only for the reaction temperature range called 'the SNCR temperature window'. It is a narrow temperature range defined in various ways in the literature, which makes it difficult to evaluate the DeNOx system's efficiency. Therefore, this study attempts to approximate the relationship between SNCR system efficiency and the flue gas temperature. The approximation was performed on the basis of literature data and verified using data from an experiment. Measurements were performed in a Polish boiler with a maximum continuous rating of $230 \mathrm{t} / \mathrm{h}$. The verified, evaluated function could be used to forecast efficiency of SNCR systems in existing units that use urea or ammonia as a reagent. The approximation results are polynomial functions that depend on flue gas temperature, which fit the literature data with the coefficient of determination $\mathrm{R}^{2}=0.83-0.86$. Therefore, these equations could be used by the designer or operator of the boiler for preliminary determination of current SNCR system efficiency.
\end{abstract}

\section{Introduction}

The SNCR (Selective Non-Catalytic Reduction) system efficiency is defined by the equation:

$$
\eta_{S N C R}=\frac{S_{1}-S_{2}}{S_{1}}, \%
$$

$\mathrm{S}_{1}$ - concentration of $\mathrm{NO}_{\mathrm{x}}$ in flue gas, without the SNCR system, $\%$.

$\mathrm{S}_{2}$ - concentration of $\mathrm{NO}_{\mathrm{x}}$ in flue gas, with the SNCR system, $\%$.

Its value is appropriately high only for a specific reaction temperature range called 'the SNCR temperature window'. Diagrams presenting the relationships between $\eta_{S N C R}$ and flue gas temperature are in references [1-6]. There are also relationships between flue gas temperature and ammonia slip ; Fig. 1 shows unified charts from the literature data for urea as a reagent and Fig. 2 shows these for ammonia.

\footnotetext{
*Corresponding author: marek.pronobis@polsl.pl
} 


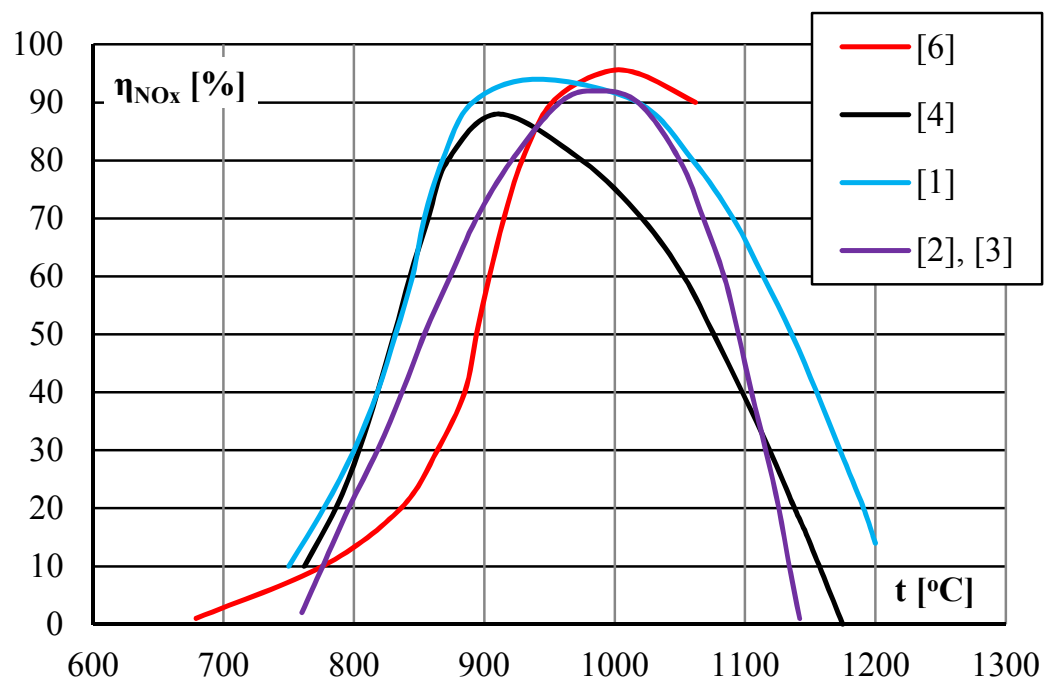

Fig. 1 The SNCR system efficiency as a function of the flue gas temperature, using urea as a reagent

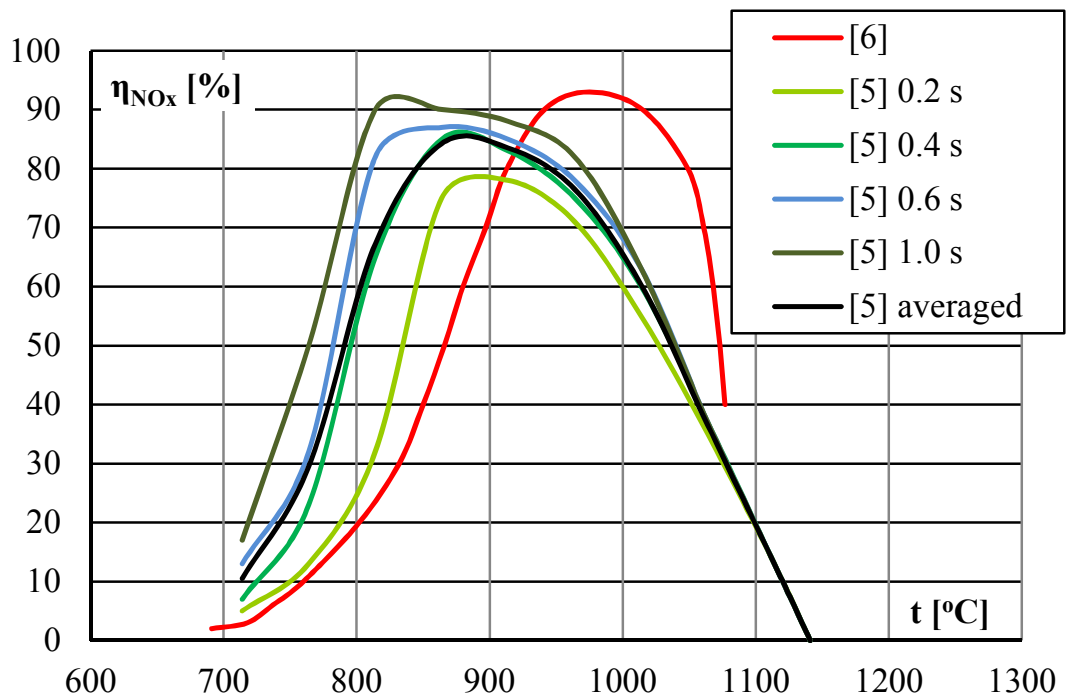

Fig. 2 The SNCR system efficiency as a function of flue gas temperature, using ammonia as a reagent

The SNCR temperature window range is relative and depends on the assumed value of the SNCR system's efficiency. Fig. 3 shows the 'old operating range' with a minimal $\eta_{S N C R}$ value of $45 \%$; however, if the $\mathrm{DeNO}_{\mathrm{x}}$ system efficiency had to be higher, the temperature range would be significantly reduced. In [7] the SNCR temperature window is about $850-1100{ }^{\circ} \mathrm{C}$ for urea, whereas in $[2,3]$ it is about $880-1080{ }^{\circ} \mathrm{C}$ for urea and for ammonia (Fig. 3). 


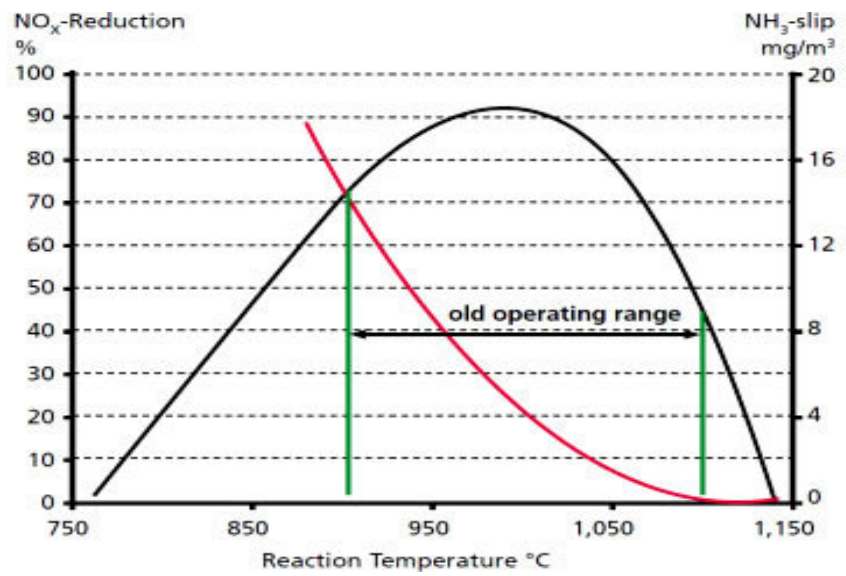

Fig. 3 The SNCR system efficiency and the ammonia slip as a function of the flue gas temperature [3]

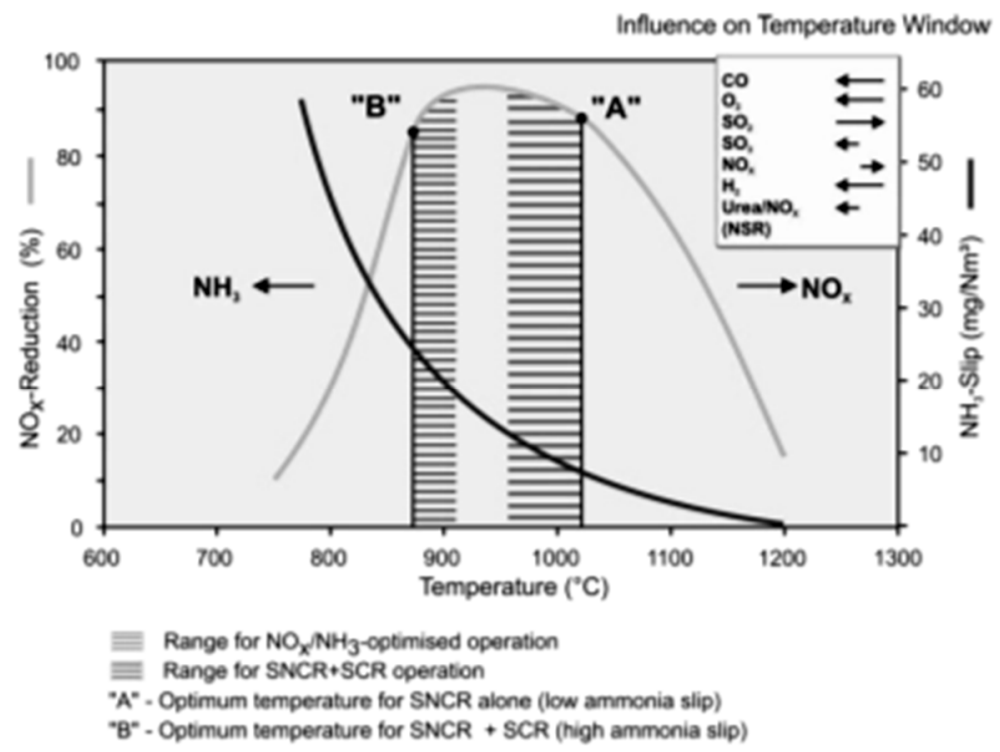

Fig. 4 The SNCR system efficiency and the ammonia slip as a function of the flue gas temperature [1]

The different course of the relationship between $\eta_{S N C R}$ and the flue gas temperature is presented in [4, 6]. In [5], the SNCR system efficiency reached values above $90 \%$ when ammonia was used as the reagent. The lab-scale tests were performed in an isolated tubular reactor in which full mixing of reagent and flue gas occurred in reaction times above $0.2 \mathrm{~s}$ (Fig. 2). Reaction time $\tau_{p}$ has a meaningful impact on $\mathrm{NO}_{\mathrm{x}}$ non-catalytic reduction. Decreased $\tau_{p}$ causes a narrowing of the SNCR temperature window for which $\eta_{S N C R}$ is above $60 \%$ - from range of $780-1020{ }^{\circ} \mathrm{C}\left(\tau_{p}=1 \mathrm{~s}\right)$ to $830-1000{ }^{\circ} \mathrm{C}\left(\tau_{p}=0.2 \mathrm{~s}\right)$, corresponding to a temperature range change $\Delta t$ of 240 to $170 \mathrm{~K}$. Decreased $\tau_{p}$ also decreases the maximal value of $\eta_{S N C R}$ by on average about $10 \%$ (Fig. 2).

Reaction time significantly depends on the flue gas temperature. For temperatures above $950{ }^{\circ} \mathrm{C} \mathrm{NO}_{\mathrm{x}}$ reduction occurs in less than $0.1 \mathrm{~s}$, whereas for $850{ }^{\circ} \mathrm{C}$ the requisite time is about $0.5 \mathrm{~s}$ [2,9]. Changing $\tau_{p}$ from 0.1 to $0.5 \mathrm{~s}$ is related to a flue gas distance of $1-5 \mathrm{~m}$, assuming the typical velocity of $10 \mathrm{~m} / \mathrm{s}$. Therefore, from the level of reactant injection to 
the level of appropriate reduction there must be several meters of space in which the flue gas temperature attains the SNCR temperature window.

The most important issue for $\mathrm{NO}_{\mathrm{x}}$ reduction efficiency is an appropriate choice of reagent injection location; if it is located in an area with flue gas temperatures above the range of the SNCR temperature window, ammonia oxidation would occur, which increases the NO concentration in flue gas, whereas $\mathrm{NH}_{3}$ slip decreases to zero. In temperatures below the SNCR temperature window, a weak reactant conversion occurs, which results in increased $\mathrm{NH}_{3}$ slip.

The appropriate mixing of reactant with flue gas is also necessary to obtain efficient $\mathrm{NO}_{\mathrm{x}}$ reduction. Optimal reagent droplet size is a meaningful issue because excessively large drops of reagent decrease the rate of evaporation at high flue gas temperatures and increase $\mathrm{NH}_{3}$ slip at lower temperatures. Excessively small drops result instead in rapid reagent evaporation, which causes a deterioration of $\mathrm{NO}_{\mathrm{x}}$ reduction.

Reactant droplets (urea solution or ammonia water) heat very slowly at the initial moment of injection because of heat removal through evaporation. Drop temperature increases by an average of $60-80 \mathrm{~K}$ and is unrelated to the flue gas temperature [10] reduction of $\mathrm{NO}_{\mathrm{x}}$ does not occur during the initial phase. Later, due to the high pressure of ammonia vapour, $\mathrm{H}_{2} \mathrm{O}$ is evaporated straight away and nitrogen compounds $\left(\mathrm{NH}_{2}, \mathrm{NH}_{3}\right)$ are released and heated immediately due to radiation. Their temperature becomes equal to the local flue gas temperature, which must be in the range of the SNCR temperature window for $\mathrm{NO}_{\mathrm{x}}$ reduction to occur.

Urea could be injected deeper into the furnace than ammonia, because the reaction between urea and $\mathrm{NO}_{\mathrm{x}}$ could occur only after complete evaporation of the solution drops. Using urea solution as a reagent prevents from its release in a cool area near the furnace water-walls and thus avoids generating $\mathrm{NH}_{3}$ slip. Therefore, using urea as the reagent enables its injection into areas of higher temperatures than in the case of using ammonia, which is a significant facilitation in boiler technology.

The advantage of using ammonia water is the rapidity of its evaporation and reaction with nitrogen oxide; therefore, in the case of reagent injection between the closely spaced heating surfaces in the boiler, ammonia water is preferred as a reagent. Other advantage of ammonia is its lesser propensity to cause corrosion of a heating surfaces.

There is also a solution combining both reagents, in which urea is dissolved in ammonia water [11]. Such a system is not a part of presented approximations.

\section{The results of approximation}

Figs. 5 and 6 show the approximation of the relationship between the SNCR system efficiency and the flue gas temperature for urea and ammonia as reagents. They were evaluated through the regression of values from Figs. 1 and 2.

The calculation of $\eta_{S N C R}$ must be performed until the trend lines reach the $x$-axis in the charts. It must be assumed that $\eta_{S N C R}=0$ for the temperatures not included in the range of $740-1220{ }^{\circ} \mathrm{C}$ for urea and $725-1162^{\circ} \mathrm{C}$ for ammonia.

As mentioned before, the $\mathrm{NO}_{\mathrm{x}}$ reduction efficiency depends on the flue gas composition and various operational parameters. However, the local contents of $\mathrm{H}_{2}, \mathrm{CO}$ or $\mathrm{SO}_{3}$ as well as the reagent droplets' residence time are not measured in industrial practice. Generally, only the temperature distribution at the SNCR system level is measured through acoustic [7] or HVT pyrometers [12]. Therefore the flue gas temperature is the only variable in the proposed correlations.

Due to measuring only one variable the resulting functions cannot be very accurate. Nonetheless they are very useful for estimating the SNCR system efficiency when lacking specific process data. 


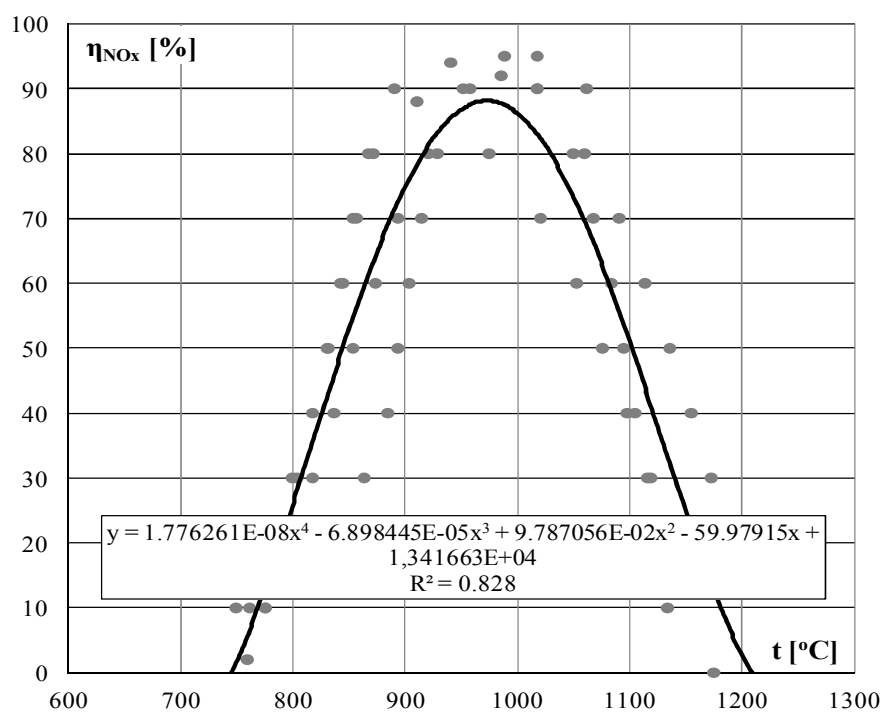

Fig. 5 The approximation of the relationship between the SNCR system efficiency and the flue gas temperature when using urea as a reagent

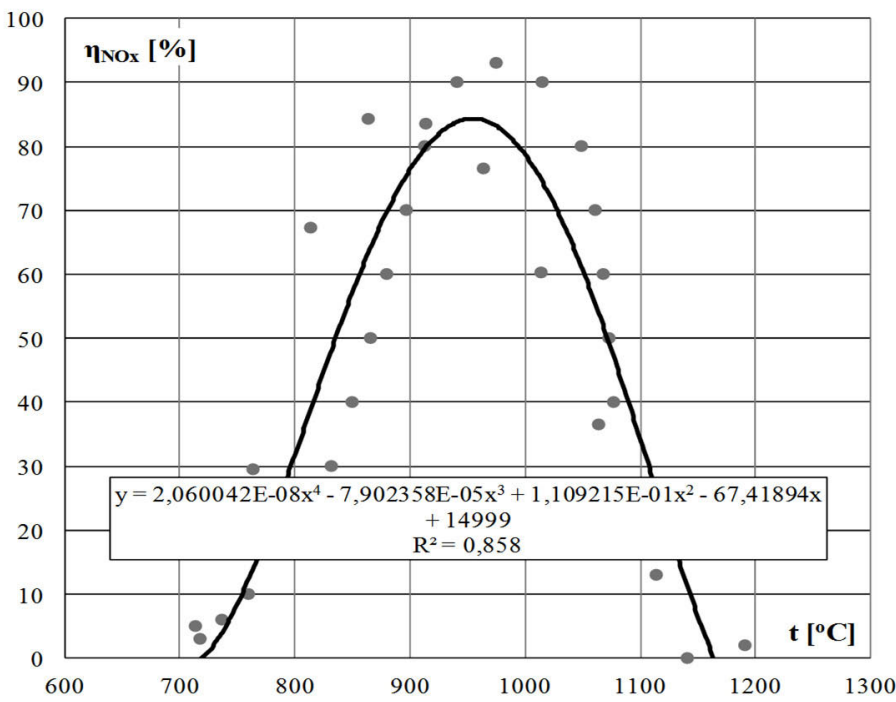

Fig. 6 The approximation of the relationship between the SNCR system efficiency and the flue gas temperature when using ammonia as a reagent

The values of the coefficient of determination $\mathrm{R}^{2}\left(\mathrm{R}^{2}=0.828\right.$ and 0.858$)$ mean that more than $80 \%$ of the $\eta_{S N C R}$ depends on the flue gas temperature - the remaining part consists of the influences of other variables.

The obtained correlations denote that the SNCR temperature window values are higher when urea is used as a reactant than when ammonia is used. In the case of urea the maximal value of the SNCR system efficiency is $88 \%$ at about $970{ }^{\circ} \mathrm{C}$ (Fig. 5), whereas for ammonia it is $84 \%$ at about $950{ }^{\circ} \mathrm{C}$ (Fig. 6). From these developed correlations, the temperature for maximum efficiency when using urea is slightly lower than that reported in [6], while the corresponding temperature for the $\mathrm{NH}_{3}$ is the same. 


\section{The results of measurements in an existing boiler}

The SNCR system efficiency was calculated on the basis of measurements performed in an existing boiler with a maximum continuous rating of $230 \mathrm{t} / \mathrm{h}$. Figs. 7, 8 and 9 show the locations of the SNCR reagent injection points. The system consists of 6 nozzles on the furnace front wall (marked as X, Y, Z, X', Y' and Z'), 3 nozzles on the furnace right wall (10 and 8 ) and 3 on the furnace left wall (36 and 9).

The points located on the furnace side walls are arranged nearly vertically:

- on the furnace right wall: ca $1010 \mathrm{~mm}$ from the tube row separating the furnace and the boiler convection section,

- on the furnace left wall: ca $1700 \mathrm{~mm}$ from the mentioned row of tubes.

Nozzles located at those points are oriented at an angle of $30^{\circ}$ to the furnace's front wall.

The points located at the furnace front wall form an irregular band with an average height of $1533 \mathrm{~mm}$ above the reference level $(19.25 \mathrm{~m})$. The maximum difference between the heights of the ports is $770 \mathrm{~mm}$. All nozzles located at the furnace's front wall are arranged horizontally.

Such nozzle locations are expedient in terms of SNCR reagent injection into the empty space at the end of the furnace. Placing them further, into the area of lower flue gas temperatures, was excluded because of the convection surfaces placed there.

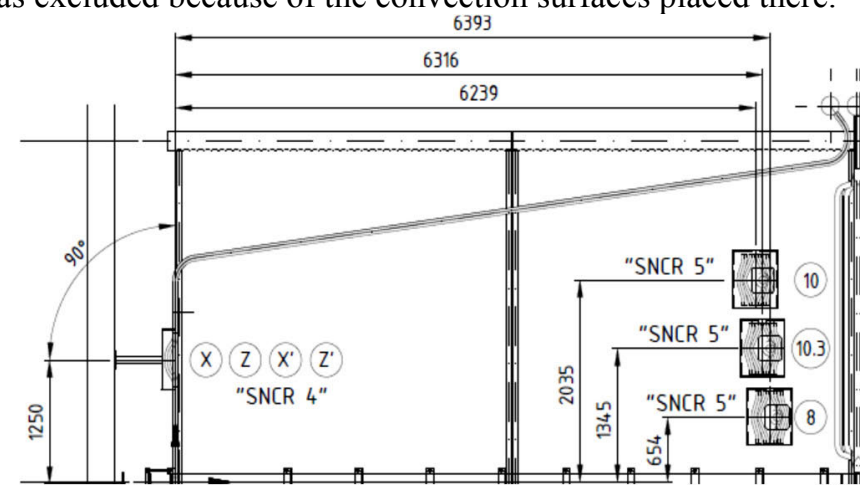

Fig. 7 The SNCR nozzle locations at the furnace's right wall

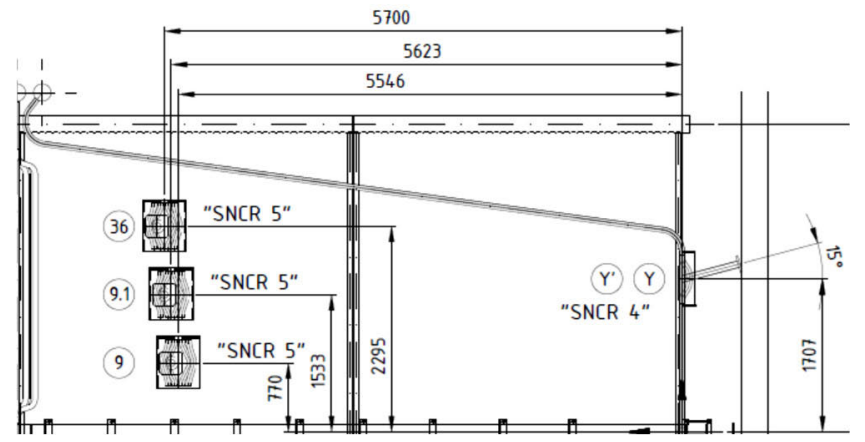

Fig. 8 The SNCR nozzle locations at the furnace's left wall 


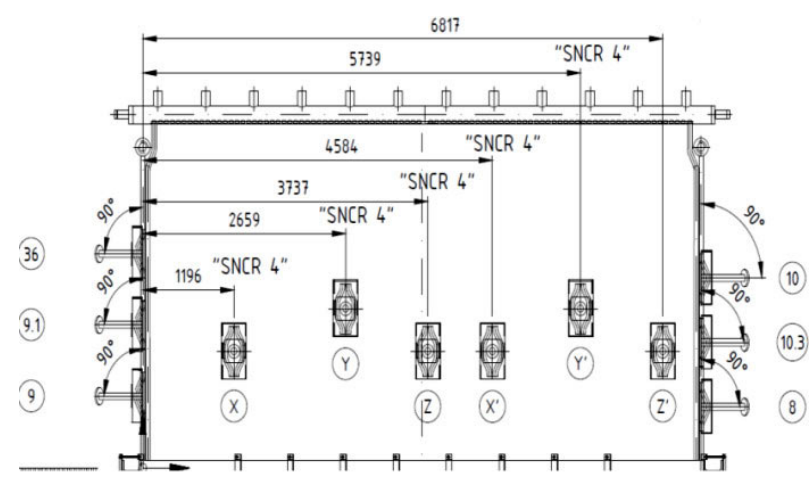

Fig. 9 The SNCR nozzle locations at the furnace's front wall

To evaluate the accuracy of the nozzle locations the measurement of flue gas temperature was performed using a bare thermocouple that was inserted into the boiler at a 1-2 m depth. Table 1 shows the obtained measurement data.

Such a measurement method is characterized by an inaccuracy resulting from the radiation of some part of the heat from the thermocouple junction to the relatively cold furnace water-walls and other heating surfaces. Thus, the measured flue gas temperatures are lower than in reality. The inaccuracy could be determined on the basis of the chart shown in Fig. 10 [13]. The measurement results refer to the case when the measured flue gas temperature $T_{g}[K]$ is higher than the effective temperature of the surroundings $T_{\infty}[K]$ (marked as the 'upper layer').

Using the chart shown in Fig. 10 the real values of the flue gas temperature were calculated (Table 1). $\mathrm{T}_{\infty}$ was calculated as the geometric average of the external furnace water-wall temperature as well as the flue gas temperature measured at each point. The results of the calculations confirm that the underestimation of the flue gas temperature could exceed $200 \mathrm{~K}$.

The measurements were performed at a maximum distance of $2 \mathrm{~m}$ from the furnace walls. Because the furnace depth and width are about $7.5 \mathrm{~m}$ each, evaluation of the flue gas temperatures in the middle of furnace was made on the basis of the approximation shown in Fig. 11. The flue gas temperatures measured at the furnace's front wall are marked as black circles (at $2 \mathrm{~m}$ depth) and black triangles (at $1 \mathrm{~m}$ depth). The flue gas temperatures measured at the furnace's left and right walls are marked as red circles (at $2 \mathrm{~m}$ depth) and red triangles (at $1 \mathrm{~m}$ depth).

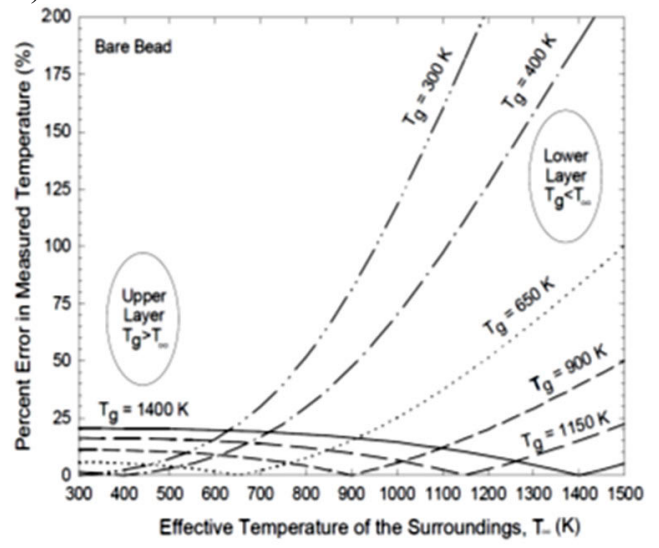

Fig. 10 The accuracy of the flue gas temperature measurement using a bare thermocouple [13] 
Table 1 Measured and calculated flue gas temperature values $\left[{ }^{\circ} \mathrm{C}\right]$

\begin{tabular}{|c|c|c|c|c|}
\hline \multirow{2}{*}{$\begin{array}{c}\text { Measuring } \\
\text { point }\end{array}$} & \multicolumn{2}{|c|}{ Measured values } & \multicolumn{2}{c|}{ Real values (calculated) } \\
\cline { 2 - 5 } & $1 \mathrm{~m}$ & $2 \mathrm{~m}$ & $1 \mathrm{~m}$ & $2 \mathrm{~m}$ \\
\hline $\mathrm{X}$ & 967 & 1045 & 1109 & 1203 \\
\hline $\mathrm{Y}$ & 960 & 1041 & 1101 & 1199 \\
\hline $\mathrm{Z}$ & 989 & 1088 & 1140 & 1279 \\
\hline $\mathrm{X}^{\prime}$ & 975 & 1101 & 1125 & 1307 \\
\hline $\mathrm{Y}^{\prime}$ & 953 & 1060 & 1094 & 1247 \\
\hline $\mathrm{Z}^{\prime}$ & 969 & 1030 & 1112 & 1186 \\
\hline 10 & 1005 & 1040 & 1158 & 1198 \\
\hline 8 & 1000 & 1105 & 1153 & 1312 \\
\hline 36 & 1025 & - & 1181 & - \\
\hline 9 & 1015 & 1027 & 1170 & 1183 \\
\hline
\end{tabular}

Missing values were calculated on the basis of the distribution of the measured values and by averaging adjacent data. It was assumed that the distribution of the measured values at a depth of $2 \mathrm{~m}$ remains steady in the further part of the duct. Thus, the set of 10 temperature values was created; each represents $10 \%$ of the duct width area. At $1 \mathrm{~m}$ from the furnace's front wall the flue gas temperatures have lower values than at the same distance from the furnace's side walls; therefore, it was assumed that the flue gas temperature at $1 \mathrm{~m}$ from the furnace's front wall is, on average $1114{ }^{\circ} \mathrm{C}$. As a result, the flue gas temperature distribution, marked as white circles in Fig. 11, is valid for the entire duct length ( $x$-coordinate) with the exception of an area of $1 \mathrm{~m}$ in width at the furnace's front wall.

That (or similar) simplification is necessary due to the relatively low number of measurement points. In the future, with a more accurate flue gas temperature measurement, it would be possible to improve the verification of the obtained approximations.

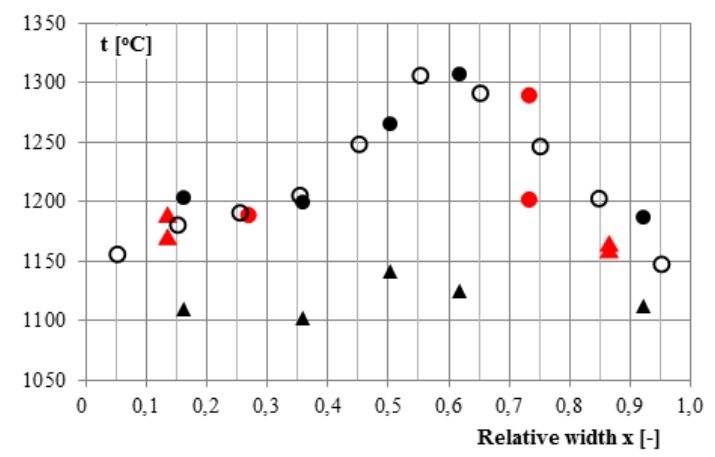

Fig. 11 The measured and the assumed flue gas temperatures
A Front $1 \mathrm{~m}$
- Front $2 \mathrm{~m}$
O Assumed mean temperature of $10 \%$ section of flue gas duct

Calculations of the SNCR system's efficiency were performed on the basis of the NO concentration in flue gas measurements. Measurements were executed during system 
operation and when the system was deactivated via. Siemens ULTRAMAT 23 gas analysers and conducted by the staff of the Division of Boilers and Steam Generators of the Silesian University of Technology and the staff of the Process Analytics and Chromatography Division of the Siemens Company.

The obtained $\eta_{S N C R}$ is about $8 \%$. It has to be noticed that this value is relatively low for industrial conditions. The gas analysers used here are characterised by an inaccuracy of about $\pm 2 \%$; due to this, the inaccuracy of $\eta_{S N C R}$ determination is about $\pm 3 \%$.

\section{The results of comparison between the measured and calculated data}

The results of calculations are shown in Table 2. Calculations were performed on the basis of the approximation from Fig. 5 for the data from Fig. 11.

The average value of $\eta_{S N C R}$ was calculated as the weighted arithmetic mean with the distances in the furnace to which they correspond to as weights.

Table 2 The results of $\eta_{S N C R}$ calculation on the basis of the obtained approximation and measured data

\begin{tabular}{|c|c|c|c|c|c|}
\hline $\begin{array}{l}\text { Relative } \\
\text { width }\end{array}$ & $\begin{array}{l}\text { The flue gas } \\
\text { temperature } \\
\text { (side walls) }\end{array}$ & $\begin{array}{c}\text { The SNCR } \\
\text { system efficiency } \\
\text { (side walls) }\end{array}$ & $\begin{array}{l}\text { The flue gas } \\
\text { temperature } \\
\text { (front wall) }\end{array}$ & $\begin{array}{c}\text { The SNCR } \\
\text { system efficiency } \\
\text { (front wall) }\end{array}$ & $\begin{array}{l}\text { The SNCR } \\
\text { system } \\
\text { efficiency } \\
\text { (average) }\end{array}$ \\
\hline $\mathbf{x}[-]$ & $\operatorname{tfg}_{-} s w\left[{ }^{\circ} \mathrm{C}\right]$ & nSNCR_sw $[\%]$ & $\operatorname{tfg}_{f} f w\left[{ }^{\circ} \mathrm{C}\right]$ & nSNCR_fw $[\%]$ & nSNCR [\%] \\
\hline 0,05 & 1155 & 22 & 1114 & 44 & 25 \\
\hline 0,15 & 1175 & 12 & 1114 & 44 & 17 \\
\hline 0,25 & 1190 & 6 & 1114 & 44 & 11 \\
\hline 0,35 & 1202 & 2 & 1114 & 44 & 8 \\
\hline 0,45 & 1248 & 0 & 1114 & 44 & 6 \\
\hline 0,55 & 1305 & 0 & 1114 & 44 & 6 \\
\hline 0,65 & 1290 & 0 & 1114 & 44 & 6 \\
\hline 0,75 & 1245 & 0 & 1114 & 44 & 6 \\
\hline 0,85 & 1200 & 3 & 1114 & 44 & 8 \\
\hline 0,95 & 1145 & 27 & 1114 & 44 & 29 \\
\hline \multicolumn{5}{|r|}{ Average } & 12 \\
\hline
\end{tabular}

As mentioned before, the estimated value of $\eta_{S N C R}$ in an existing boiler is about $8 \%$.

To match the values of $\eta_{S N C R}$ from Figs. 1 and 2 to the measured values in existing industrial facilities implementation of a correction coefficient, $\Delta \eta_{S N C R}$ is needed:

$$
\eta_{S N C R}=\eta_{S N C R(\text { calculated })} \quad \Delta \eta_{S N C R}[\%]
$$

For the case described above, the $\Delta \eta_{S N C R}$ calculated from eq. (2) is $4 \%$.

Taking into account the inaccuracy of NO measurement $( \pm 3 \%)$, the real value of $\Delta \eta_{S N C R}$ would be 1 or $7 \%$.

The $\triangle \mathrm{\eta}$ SNCR cannot take the form of a multiplier, because in the case of low SNCR system efficiency values, the inaccuracy of NO measurements would give fluctuations of $\triangle \eta \mathrm{SNCR}$ at the level of several tens of percent. 


\section{Conclusions}

The approximations obtained here could be used by a boiler designer or operator for preliminary determination of the current SNCR system efficiency; however, in most cases, implementation of a correction coefficient is necessary to reduce the inaccuracy of approximations with reference to measured values. The inaccuracy of approximations is a standard issue that results from its nature. Nonetheless, such functions, representing the relationship between the SNCR system efficiency and the flue gas temperature, are very useful when one lacks specific operation data.

Future work will focus on further verification of the evaluated approximations as well as on evaluation of the correction coefficient.

The investigations presented in this paper were financed within the research program BKS/103/RIE5/2015.

\section{References}

1. B. von der Heide, Advanced SNCR Technology for Power Plants (POWER-GEN International, Las Vegas, 2011)

2. Z. Teuber, T. Motyczyńska, SNCR - niekatalityczna metoda redukcji $N O_{x}$ dla dużych bloków energetycznych [SNCR - the non catalytic reduction of $N O_{x}$ emissions for big power plants] (11 $1^{\text {th }}$ International Conference on Boiler Technology, Szczyrk, 2010) [in Polish]

3. W. Schüttenhelm, P. Reynolds, SNCR for Low NOx Emissions - Case Study of a Swedish Waste-to-Energy Plant (on-line)

4. W. H. Sun, Selective Non Non-Catalytic Reduction: Overview (WPCA/Duke $\mathrm{NO}_{\mathrm{x}}$ Seminar, North Carolina, 2005)

5. D. Wojichowski, SNCR System Design, Installation, and Operating Experience (DOE NETL, Pittsburgh, 2002)

6. J. K. Sorrels, D. D. Randall, C. Richardson Fry, K. S. Schaffner, Selective Noncatalytic Reduction (on-line)

7. W. Schüttenhelm, K. H. Huber, Z. Teuber, VGB PowerTech 12 (2013)

8. J. Kuropka, M. A. Gostomczyk, Ochrona środowiska 463 (1996) [in Polish]

9. A. Aleksik, Redukcja tlenku azotu w przemystowym spalaniu odpadów przy zastosowaniu wtrysku mocznika [Reduction of nitrogen oxide using urea injection in an industrial waste incineration] ( $\mathrm{PhD}$ thesis, Wrocław University of Science and Technology, Wrocław, 1997) [in Polish]

10. J. Krüger, W. Gotthardt, K. Rieger, T. Franke, S. Krüger, VGB PowerTech 4 (2012)

11. B. von der Heide, Möglichkeiten und Grenzen der SNCR [Possibilities and limitations connected with SNCR] (Conference on the Waste Management and Energy, Berlin, 2012) [in German]

12. S. Kalisz, Sz. Ciukaj, K. Mroczek, T. Kress, R. Wejkowski, M. Pronobis, H. Kubiczek, Impact of halloysite fuel additive on $650 \mathrm{t} / \mathrm{h}$ PC boiler co-firing biomass. Part I deposition characteristics (12 $2^{\text {th }}$ International Conference on Boiler Technology, Szczyrk, 2014)

13. L. G. Blevins, Behavior of Bare and Aspirated Thermocouples in Compartment Fires (33 ${ }^{\text {rd }}$ National Heat Transfer Conference, Albuquerque, 1999) 